\title{
Proposição de Modelo para Mensuração do Valor Percebido no Ambiente Logístico B2B
}

\section{Proposing a Model for Measuring the Perceived Value for B2B Logistics Environment}

\author{
Clarice Mara Sousa e Silva ${ }^{1}$, Stella Naomi Moriguchi ${ }^{1}$, José Eduardo Ferreira Lopes ${ }^{1}$ \\ ${ }^{1}$ Universidade Federal de Uberlândia, UFU, Brasil \\ Correspondência: Clarice Mara Sousa e Silva, Endereço: Rua Rivalino Pereira, 846, $2^{\circ}$ Andar, Martins, CEP: \\ 38400344, Uberlândia, MG. Tel.: 5534 3231-2716. E-mail: claricemara@ hotmail.com
}

Recebido: 23 de setembro de 2016 Aceito: 20 de julho de 2017 Publicado: 31 de outubro de 2017

DOI: http://dx.doi.org/10.21714/1679-18272016v14n2.p327-342

\begin{abstract}
Resumo
Este artigo tem por objetivo apresentar um modelo para mensuração do valor percebido por PMEs-Pequenas e Médias Empresas que contratam serviços logísticos terceirizados. Internacionalmente, diversas pesquisas na área de percepção de valor no ambiente B2B vêm sendo realizados, contudo estudos teóricos e aplicados no Brasil são escassos, focando suas análises em atributos objetivos em detrimento de análises de percepção de alta abstração. A partir de uma análise de conteúdo de pesquisas internacionais, selecionou-se 10 construtos relacionados às métricas de percepção de valor no ambiente $\mathrm{B} 2 \mathrm{~B}$. Na segunda etapa, realizou-se um levantamento junto a uma amostra não-probabilística, extraída da base de dados de um grande prestador de serviços logísticos de entrega de remessas que opera em âmbito nacional. Como resultado da aplicação de análise fatorial exploratória e confirmatória e de modelagem de equações estruturais, utilizando PLS - Partial Least Square, propõe-se um modelo com 5 construtos: reputação $(\mathrm{p}=0,44)$, valor do relacionamento $\left(\mathrm{R}^{2 \mathrm{Ajus}}=0,27\right)$, confiança $\left(\mathrm{R}^{2 \mathrm{Ajus}}=0,25\right)$, boca-a-boca $\left(\mathrm{R}^{2 \mathrm{Ajus}}=0,35\right)$, e intenção de recompra $\left(\mathrm{R}^{2 \mathrm{Ajus}}=0,24\right)$. Os resultados evidenciam que as PMEs valorizam parceiros logísticos de boa reputação como forma de minimizar os problemas de gestão da cadeia de suprimentos. Além disto, verificou-se a importância preponderante do bocaa-boca com um consequente do valor percebido.
\end{abstract}

Palavras-chave: Valor Percebido; Logística; B2B; PMEs - Pequenas e Médias Empresas.

\begin{abstract}
This article aims to present a model for measuring the value perceived by SMEs - Small and Medium Enterprises employing contract workers logistics services. Internationally, several studies in the perceived value area in the B2B environment have been conducted, however theoretical and applied studies in Brazil are scarce, focusing their analysis on objective attributes over of high abstraction perception analysis. From an international research content analysis, it was selected 10 constructs related to the perception of value metrics in the B2B environment. In a second step, was held a survey with a non-probabilistic sample, extracted from the database of a large provider of logistics services delivering shipments which operates nationwide. As a result of the application of Exploratory Factor Analysis and Confirmatory and Structural Equation Modeling using PLS - Partial Least Square, it is proposed a model with five constructs: reputation $(p=0,44)$, relationship value ( 2 Adjus $=0,27)$, trust ( $\mathrm{R} 2$ Adjus $=0,25)$, word-of-mouth ( $\mathrm{R} 2$ Adjus $=0,35)$, and repurchase intention ( $\mathrm{R} 2$ Adjus $=0,24)$. The results show, in the measurement of perceived value, that SMEs value logistics partners in good standing in order to minimize management problems in the supply chain faced in their day-to-day. In addition, there was the overwhelming importance of word-of-mouth with a consequent the perceived value.
\end{abstract}

Keywords: Perceived Value; Logistics; B2B; SMEs - Small and Medium-Sized Enterprises.

Esta obra está licenciada sob uma Licença Creative Commons Attribution 3.0.

\section{Introdução}

No âmbito internacional, pesquisas na área de percepção de valor no ambiente B2B apresentam resultados que clarificam o fenômeno do valor percebido neste contexto (MOLINARI; ABRATT; DION, 2008; BLOCKER, 2011). Métricas de percepção de valor têm sido consideradas, dentre outros aspectos, importantes para a 
construção de vantagem competitiva (WOODRUFF, 1997; PARASURAMAN, 1997). A construção do valor percebido sob a ótica do consumidor é complexa e necessita considerar dimensões de alta abstração, ampliando o uso de atributos em pesquisas de investigação deste conceito (ZEITHAML, 1998; RAVALD; GRÖNROOS, 1996; WOODRUFF, 1997). No Brasil, diversas pesquisas do segmento logístico têm se desenvolvido no campo de avaliação de atributos de valor (FIGUEIREDO et al, 2007; TONTINI; ZANCHETT, 2010; MARTINS et. al, 2011; MARTINS; XAVIER, 2011), considerados importantes no processo de compra (escolha), mas insuficientes para o entendimento da construção da percepção de valor, que perpassa consequências, usos e relacionamento com o cliente (ZEITHAML, 1998; WOODRUFF, 1997).

No Brasil, a pesquisa de valor percebido apresenta-se focada em relações B2C (BREI; ROSSI, 2005; GOSLING; LAGO, 2006; DA ROCHA; SILVA, 2006; LACERDA; MENDONÇA, 2010), enquanto a produção no campo de investigações do ambiente B2B apresenta-se escassa. Proposições de agendas de pesquisas internacionais no ambiente $\mathrm{B} 2 \mathrm{~B}$ para os próximos anos sugerem a necessidade de investigação na área de valor, aprofundando o conhecimento dos atributos considerados importantes pelos clientes e sua relação com o valor percebido, que é um direcionador do comportamento de compra dos consumidores (BOKSBERGER; MELSEN, 2011; LINDGREEN et al., 2012; WIERSEMA, 2013).

Segundo dados do SEBRAE (2013), 99\% das empresas no Brasil são empreendimentos de micro e pequeno porte e "existem cerca de 22,8 milhões de pessoas que são donos de negócio no país, resultado da soma de empregadores e conta própria", o que torna o segmento de PMEs - Pequenas e Médias Empresas - um importante campo para investigações (SEBRAE, 2013, p.11).

Gerenciar a cadeia de suprimentos de uma empresa, em especial a contratação de transportes, conduzindo-a a uma boa performance, pode proporcionar à empresa uma vantagem competitiva sustentável (PRESUTTI; MAWHINNEY, 2007), embora seja uma tarefa problemática (ELRAM; TATE; BILLINGTON, 2004; 2007). Especialmente para as PMEs (HONG; JEONG, 2006). Os desafios enfrentados na gestão de PMEs parecem ser maiores que os de grandes corporações que comumente têm equipes especializadas na gestão da contratação de serviços (PEREIRA; PEREIRA, 2014). Nas PMEs, além da escassez de recursos financeiros, pessoas, sistemas e conhecimento técnico (DRUMOND; TOALDO, 2009), a gestão de pequenas e médias empresas tem forte componente familiar e centralização na gestão, e o dono acaba por envolver-se nas decisões e atividades funcionais, muitas vezes de maneira não planejada, impactando negativamente em seus resultados (DRUMOND; TOALDO, 2009; MARTINS; XAVIER, 2011).

No Brasil, a gestão dos serviços logísticos revela-se complexa. Dados da CNT - Confederação Nacional de Transportes (CNT, 2014) indicam que, levando-se em consideração os custos totais das empresas no Brasil, a maior parcela está ligada ao transporte. Estima-se que no país os custos de transporte correspondam a cerca de $60 \%$ dos custos logísticos totais. O documento da CNT aponta ainda que, em 2008, os custos logísticos representaram $12 \%$ do PIB brasileiro. Em comparação, nos EUA, no mesmo período, estes custos representaram 9\% do PIB norte-americano. Desta forma, a gestão logística torna-se uma oportunidade de melhoria para aumento da competitividade de uma organização e do país, na medida em que a eficiência na gestão aumenta (CNT, 2014).

O documento da CNT aponta ainda que, de 2007 a 2013, houve um crescimento de $17 \%$ no licenciamento de veículos rodoviários de carga, o que denota um crescimento expressivo da demanda por serviços transporte rodoviário. No país, $61 \%$ das cargas são transportadas pelo modal rodoviário (CNT, 2014).

Dados os altos custos logísticos envolvidos (CNT, 2014), complexidades inerentes ao processo de gestão de transportes (Elram et al., 2004; 2007; MARTINS; XAVIER, 2011) e peculiaridades ligadas ao perfil dos pequenos e médios empreendedores (DRUMOND; TOALDO, 2009; MARTINS; XAVIER, 2011; SEBRAE, 2013), torna-se importante compreender mais profundamente como se formam as percepções de valor deste segmento de consumidores no ambiente $\mathrm{B} 2 \mathrm{~B}$, quando consomem e se relacionam com seus parceiros logísticos.

Desta forma, esta pesquisa tem por objetivo propor um modelo para avaliar a percepção de valor de serviços logísticos, no ambiente B2B, entre PMEs usuárias de serviços logísticos terceirizados de entrega de pequenas remessas (até $50 \mathrm{~kg}$ ). Assim, esta pesquisa buscou traduzir e adaptar os instrumentos utilizados pelas pesquisas B2B aplicadas realizadas no contexto internacional para o contexto brasileiro logístico das PMEs, bem como propor um instrumento de pesquisa adaptado ao contexto brasileiro logístico das PMEs.

\section{Referencial Teórico}

\subsection{0 que é valor percebido}

Encontram-se em estudos teóricos e aplicados diversas abordagens do que seja valor (BOWMAN; AMBROSINI, 2000; BOKSBERGER; MELSEN, 2011; LINDGREEN et al., 2012). Dentre as possibilidades, destaca-se a perspectiva de valor percebido (Perceived Value). Para a presente pesquisa, considerou-se a 
perspectiva de valor percebido como valor para o cliente, pois utiliza o ponto de vista do cliente nos julgamentos de valor (MELLO; LEÃO, 2008).

Zeithaml (1988), Ravald e Grönroos (1996) e Woodruff (1997) apresentam valor percebido como um processo complexo e de alta abstração, desenvolvido em vários episódios e relacionado a expectativas do cliente. Para Zeithaml (1988), valor percebido é a avaliação global que o consumidor faz da utilidade de um produto, baseando-se em sua percepção entre o que é recebido (benefícios) e o que é dado (sacrifícios), para obter tais benefícios.

Ravald e Grönroos (1996) ampliam o conceito de Zeithaml (1988), ligando-o a episódios de benefícios e sacrifícios vividos pelo consumidor. Para esses autores, é a frequência destes episódios e os efeitos da manutenção de um relacionamento que criam um 'episódio de valor'. $\mathrm{O}$ valor dos relacionamentos é essencial na opinião destes pesquisadores.

Para Woodruff (1997), atributos de valor desempenham um papel fundamental no processo de compra. No modelo proposto pelo autor, os atributos de valor atuam na fase inicial do processo de compra e formação da percepção, quando o cliente aprende a pensar sobre produtos como pacotes de atributos específicos. É após a compra e o uso que o cliente começa a formar novos níveis de reflexão e o seu conceito de valor. Woodruff (1997) considera que o valor percebido pelo cliente está ligado à sua satisfação, e esta pode estar ligada às medidas ou dimensões como boca-a-boca, intenção de recompra e lealdade, por exemplo. Medir estes construtos é importante para se entender como os clientes percebem valor. Por isto, a distinção entre atributos de valor e seus efeitos na percepção torna-se importante para o entendimento do conceito de valor percebido (Zeithaml, 1988).

\subsection{Escalas de mensuração relacionadas ao valor percebido}

A mensuração de valor percebido e seus construtos relacionados - como, por exemplo, satisfação e qualidade - é comumente estudada no campo de pesquisa de marketing por meio de escalas e modelos mais frequentemente desenvolvidos em ambientes B2C. A título de ilustração, pode-se citar a escala SERVQUAL (PARASURAMAN; ZEITHAML; BERRY, 1985), a Abordagem Hierárquica de Percepção de Qualidade do Serviço (BRADY; CRONIN Jr, 2001) e o ACSI - American Customer Satisfaction Index (FORNELL et al., 1994).

Em que pese a grande contribuição para ampliação da base de conhecimento científico que estes modelos ofereceram, os instrumentos e modelos de medição de valor e satisfação percebidos não atendiam plenamente ao contexto do ambiente B2B. Por suas características singulares, este ambiente necessitava de modelos e instrumentos distintos (LAPIERRE, 2000). Uma importante pesquisa multidimensional ligada à percepção de valor no ambiente B2B foi publicada por Patterson e Spreng (1997). Nela, os pesquisadores sugeriram uma clara relação entre valor percebido, satisfação e intenções de recompra.

Lapierre (2000) propôs 13 drivers de valor percebido e possibilitou clarificar ainda mais a interações entre construtos de percepção de valor no ambiente B2B.

Ulaga (2001) e Ulaga e Chacour (2001) estabeleceram uma relação de relevante importância para o ambiente B2B: qualidade percebida pelo cliente e satisfação do cliente são dois construtos interligados e devem ser levados em consideração em conjunto.

Eggert e Ulaga (2002) estabeleceram alta correlação entre os construtos de valor percebido pelo cliente, satisfação do cliente, intenção de recompra, busca de outras alternativas, e boca-a-boca. Os resultados indicaram a satisfação como um "melhor preditor para resultados comportamentais do que valor percebido pelo cliente" (EGGERT; ULAGA, 2002, p.113).

Em 2006, Ulaga e Eggert apresentaram nova pesquisa, associando o construto de valor do relacionamento como um antecedente aos construtos de satisfação, confiança, comprometimento, relacionando-os às intenções dos clientes em abandonar ou expandir o relacionamento B2B.

Vale ressaltar que, no Brasil, diversas pesquisas no ambiente B2B ligadas a dimensões objetivas de valor consideradas pelos clientes e seu relacionamento com o parceiro logístico foram desenvolvidas na última década (FIGUEIREDO et al., 2007; TONTINI; ZANCHETT, 2010; MARTINS et al., 2011; MARTINS; XAVIER, 2011).

\section{Método}

Inicialmente, realizou-se amplo levantamento bibliográfico nacional e internacional, buscando identificar estudos sobre valor percebido no ambiente B2B. Foram selecionadas 13 pesquisas aplicadas no campo de valor percebido, resultando em 10 construtos.

O Quadro 1 apresenta os construtos para integrar o instrumento proposto; os nomes mais usuais encontrados na literatura; os autores que já utilizaram esses construtos em suas pesquisas e os autores predominantemente utilizados para construir o instrumento para mensurar a Percepção de Valor em Ambiente B2B. A categorização 
dos construtos apresentados na pesquisa foi feita por meio de análise de conteúdo, conforme Bardin (2011).

Seguindo as recomendações de Hair et al. (2005) para verificação da confiabilidade e validade, construído o questionário, este foi submetido à apreciação de três especialistas, chegando-se à versão final do instrumento de coleta de dados com 37 variáveis. Utilizou-se escalas do tipo Likert de 7 pontos (1 - Discordo Totalmente; 7 Concordo Totalmente), conforme a maioria dos estudos aplicados no ambiente B2B. As variáveis que foram utilizadas para os 10 construtos são apresentadas no Quadro 2.

Quadro 1: Seleção dos construtos para compor o instrumento proposto

\begin{tabular}{|c|c|c|c|c|}
\hline \begin{tabular}{l|}
$\mathbf{I}$ \\
$\mathbf{t}$ \\
$\mathbf{e}$ \\
$\mathbf{m}$
\end{tabular} & $\begin{array}{c}\text { Contructo } \\
\text { para o } \\
\text { instrumento } \\
\text { proposto }\end{array}$ & $\begin{array}{l}\text { Construtos encontrados nas } \\
\text { pesquisas internacionais }\end{array}$ & Autores (ano) & $\begin{array}{l}\text { Adaptação } \\
\text { predominan } \\
\text { te }\end{array}$ \\
\hline 1 & $\begin{array}{c}\text { Valor } \\
\text { percebido }\end{array}$ & $\begin{array}{l}\text { Valor percebido, Valor, Valor } \\
\text { percebido para o cliente, } \\
\text { Percepção do cliente } \\
\text { Relacionamento, Valor do } \\
\text { relacionamento, Interação pessoal }\end{array}$ & $\begin{array}{l}\text { Patterson e Spreng (1997), Eggert e } \\
\text { Ulaga (2002), Spiteri e Dion (2004) } \\
\text { Ulaga e Eggert (2006), Molinari, } \\
\text { Abratt e Dion (2008), Gil-Saura, } \\
\text { Frasquet-Deltoro e Cervera-Taulet } \\
\text { (2009), Blocker (2011), Janita e } \\
\text { Miranda (2013) }\end{array}$ & $\begin{array}{l}\text { Ulaga e } \\
\text { Eggert } \\
(2006)\end{array}$ \\
\hline 2 & Satisfação & $\begin{array}{l}\text { Satisfação do cliente, Satisfação, } \\
\text { satisfação geral }\end{array}$ & $\begin{array}{l}\text { Eggert e Ulaga (2002), Lam et al. } \\
\text { (2004), Ulaga e Eggert (2006), } \\
\text { Rauyruen e Miller (2007), Molinari, } \\
\text { Abratt e Dion(2008), Gil-Saura, } \\
\text { Frasquet-Deltoro e Cervera-Taulet } \\
\text { (2009), Blocker (2011), Janita e } \\
\text { Miranda (2013) }\end{array}$ & $\begin{array}{l}\text { Ulaga e } \\
\text { Eggert } \\
(2006)\end{array}$ \\
\hline 3 & $\begin{array}{l}\text { Qualidade } \\
\text { do serviço }\end{array}$ & $\begin{array}{c}\text { Serviço, Qualidade geral do } \\
\text { serviço, Qualidade do serviço, } \\
\text { Qualidade do produto } \\
\text { Qualidade, Qualidade oferecida, } \\
\text { Qualidade percebida }\end{array}$ & $\begin{array}{l}\text { Patterson e Spreng (1997), Lapierre } \\
\text { (2000), Lam et al. (2004), Rauyruen } \\
\text { e Miller (2007); Molinari, Abratt e } \\
\text { Dion(2008); Blocker (2011) }\end{array}$ & $\begin{array}{l}\text { Lam et al. } \\
\quad(2004)\end{array}$ \\
\hline 4 & Preço & $\begin{array}{c}\text { Preço, Custos diretos } \\
\text { Custos de aquisição } \\
\text { Custos de operação, Sacrifício } \\
\text { percebido, Valor percebido pelo } \\
\text { cliente }\end{array}$ & $\begin{array}{l}\text { Lapierre (2000), Eggert e Ulaga } \\
\text { (2002), Spiteri e Dion (2004), Lam et } \\
\text { al. (2004), Blocker (2011) }\end{array}$ & $\begin{array}{l}\text { Eggert e } \\
\text { Ulaga } \\
(2002)\end{array}$ \\
\hline 5 & Confiança & Confiança & $\begin{array}{c}\text { Lapierre (2000), Ulaga e Eggert } \\
\text { (2006), Rauyruen e Miller (2007), } \\
\text { Gil-Saura, Frasquet-Deltoro e } \\
\text { Cervera-Taulet (2009) }\end{array}$ & $\begin{array}{l}\text { Ulaga e } \\
\text { Eggert } \\
(2006)\end{array}$ \\
\hline 6 & $\begin{array}{l}\text { Compromet } \\
\text { imento }\end{array}$ & $\begin{array}{l}\text { Comprometimento, Solidariedade } \\
\text { do fornecedor com os clientes }\end{array}$ & $\begin{array}{c}\text { Lapierre (2000), Ulaga e Eggert } \\
\text { (2006), Rauyruen e Miller (2007), } \\
\text { Gil-Saura, Frasquet-Deltoro e } \\
\text { Cervera-Taulet (2009) }\end{array}$ & $\begin{array}{l}\text { Ulaga e } \\
\text { Eggert } \\
(2006)\end{array}$ \\
\hline 7 & Reputação & $\begin{array}{l}\text { Imagem, imagem corporativa, } \\
\text { Reputação corporativa }\end{array}$ & $\begin{array}{l}\text { Lapierre (2000), Hansen, Samuelsen } \\
\text { e Silseth (2008), Janita e Miranda } \\
\text { (2013) }\end{array}$ & $\begin{array}{l}\text { Hansen, } \\
\text { Samuelsen e } \\
\text { Silseth } \\
(2008)\end{array}$ \\
\hline 8 & $\begin{array}{l}\text { Busca de } \\
\text { alternativas }\end{array}$ & $\begin{array}{l}\text { Busca de alternativas (troca de } \\
\text { fornecedor), Custos de troca }\end{array}$ & $\begin{array}{l}\text { Eggert e Ulaga (2002), Lam et al. } \\
\text { (2004), Hansen, Samuelsen e } \\
\text { Silseth(2008) }\end{array}$ & $\begin{array}{l}\text { Eggert e } \\
\text { Ulaga } \\
\text { (2002); Lam } \\
\text { et al. }(2004)\end{array}$ \\
\hline 9 & Boca-a-boca & $\begin{array}{l}\text { Boca-a-boca (indicação), } \\
\text { Lealdade do cliente } \\
\text { (recomendação) }\end{array}$ & $\begin{array}{c}\text { Ulaga e Eggert (2002), Lam et al. } \\
\text { (2004), Molinari, Abratt e Dion } \\
\text { (2008), Hansen, Samuelsen e Silseth } \\
\text { (2008) }\end{array}$ & $\begin{array}{l}\text { Lam et } \\
\text { al.(2004) }\end{array}$ \\
\hline
\end{tabular}




\begin{tabular}{|c|c|c|c|c|}
\hline & & Patterson e Spreng (1997), Eggert e & \\
1 & Intençãão de de recompra, Intenção de & Ulaga (2002), Lam et al. (2004), & Eggert e \\
expansão, Intenção de abandonar & Spiteri e Dion (2004), Ulaga e Eggert & Ulaga \\
0 & recompra & o Relacionamento, Lealdade, & (2006), Rauyruen e Miller (2007), & $(2002) ;$ \\
& & lealdade do cliente, Lealdade do & Molinari, Abratt e Dion (2008), Gil- & Lam et al. \\
& & usuário final, lealdade atitudinal, & Saura, Frasquet-Deltoro e Cervera- \\
Lealdade do cliente (padrão) & Taulet (2009), Janita e Miranda & (2004) \\
& & & (2013) & \\
\hline
\end{tabular}

Quadro 2: Instrumento de Pesquisa Proposto para Mensuração de Percepção de Valor em Ambiente B2B no Brasil - Serviços Logísticos prestados a PMEs

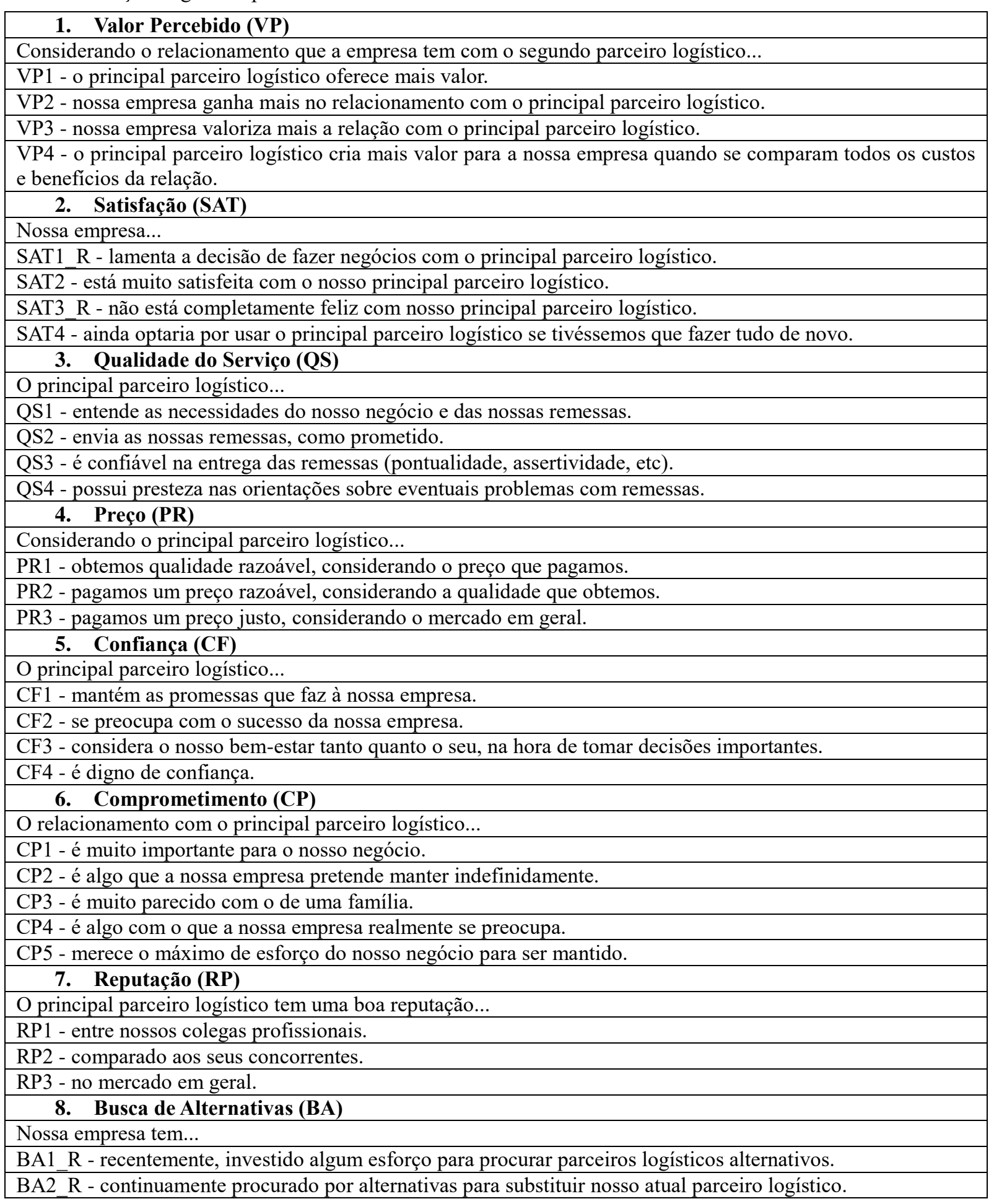




\begin{tabular}{|l|}
\hline Considere as seguintes situações: \\
\hline $\begin{array}{l}\text { BA3 - Se minha empresa trocasse atual parceiro logístico por outro fornecedor, alguns problemas tecnológicos } \\
\text { poderiam aparecer. }\end{array}$ \\
\hline BA4 - Minha empresa se sentiria insegura se tivéssemos que escolher outro parceiro logístico. \\
\hline 9. Boca-a-boca (BB) \\
\hline Eu tenho... \\
\hline BB1 - dito coisas boas acerca do atual parceiro logístico para outros colegas de profissão. \\
\hline BB2 - recomendado atual parceiro logístico a colegas de profissão que me pedem conselhos. \\
\hline BB3 - encorajado outras empresas a fazer negócios com o atual parceiro logístico. \\
\hline \multicolumn{10}{c|}{ Intenção de Recompra (IE) } \\
\hline Considere as seguintes afirmações: \\
\hline IE - Em nossa próxima necessidade de serviços logísticos, iremos usar nosso atual parceiro logístico. \\
\hline $\begin{array}{l}\text { IE - No futuro previsível nós consideraremos nosso atual parceiro logístico como parte de nosso grupo de } \\
\text { escolhas. }\end{array}$ \\
\hline IE - Nós temos a intenção de continuar a ter uma relação de compra com nosso principal parceiro logístico. \\
\hline
\end{tabular}

$\mathrm{Na}$ etapa quantitativa, após a coleta e tratamento dos dados, utilizou-se a técnica estatística de Análise Fatorial Exploratória (AFE) dos dados e todos os pressupostos da utilização da técnica como tamanho da amostra, normalidade dos dados e correlação significativa entre as variáveis foram observados (HAIR JR et al., 2009). Para verificação das validades convergente e discriminante, utilizou-se Modelagem de Equações Estruturais com PLS (MEEPLS) com os parâmetros sugeridos por Hair Jr et al. (2014). Para estes autores, a MEEPLS oferece poder estatístico satisfatório mesmo com amostras pequenas, além de atender ao objetivo de oferecer análises mais acuradas quando se quer propor modelos de predição, como no caso da presente pesquisa.

A coleta de dados foi realizada entre os dias 24 de Outubro e 11 de Novembro de 2014, utilizando-se a plataforma SurveyMonkey®. O endereço eletrônico para resposta da pesquisa foi enviado a 43.035 e-mails empresariais de clientes de pequeno e médio porte, localizados em todos os estados do país. A base de dados foi fornecida por uma importante empresa de serviços logísticos atuante em todo o território brasileiro. Detectou-se, após o envio dos e-mails, uma taxa de negativas de resposta e devoluções automáticas de e-mails da ordem de $9 \%$, reduzindo a população para 39.162 empresas. Houve um total de 153 respondentes, sendo que destes, 137 questionários $(89 \%)$ foram considerados válidos para realizar a análise. Portanto, a amostra foi selecionada por conveniência (não-probabilística).

\section{Resultados Encontrados}

\subsection{Análise fatorial exploratória}

A análise fatorial das 37 variáveis utilizadas foi validada pelo teste de esfericidade de Barlett e pelo índice de Kaiser-Meyer-Olkin (KMO) igual a 0,821, maior que 0,5 , o índice recomendado.

Em relação à extração dos fatores, utilizou-se a análise de componentes, pois o objetivo de criar uma escala de mensuração requer a diminuição de dados, conforme sugerem Hair Jr et al. (2009). A rotação VARIMAX utilizada formou 9 fatores, que explicavam $74,077 \%$ da variância.

$\mathrm{Na}$ Tabela 1, os fatores agrupados foram renomeados. Das 37 variáveis inicialmente analisadas, 6 foram excluídas. Os critérios para exclusão das variáveis considerou as diretrizes para identificação de cargas fatoriais significantes com base na amostra de 137 respondentes proposto por Hair Jr et al. (2009): cargas fatoriais abaixo de 0,50 foram excluídas da análise. Além disto, considerou-se na análise da exclusão de variáveis aquelas que apresentaram cargas fatoriais cruzadas.

Tabela 1: Matriz de Cargas Fatoriais

\begin{tabular}{|c|c|c|c|c|c|c|c|c|c|c|c|}
\hline \multirow{2}{*}{$\begin{array}{l}\text { Variá- } \\
\text { veis }\end{array}$} & \multicolumn{9}{|c|}{ Fatores } & \multirow{2}{*}{\multicolumn{2}{|c|}{ Construto }} \\
\hline & 1 & 2 & 3 & 4 & 5 & 6 & 7 & 8 & 9 & & \\
\hline RP2 & ,808 & ,231 & ,241 & , 135 & ,002 & ,048 & ,058 & ,231 & 031 & & \\
\hline RP3 & ,807 & ,228 & ,252 &, 123 & ,093 & ,092 & ,069 & 199 & ,127 & & \\
\hline RP1 & 801 & 103 & 242 & 259 & 091 & 088 & 090 & ,234 & 026 & & \\
\hline BB3 & 613 & 237 & , 191 & 158 & , 124 & 307 & 220 &,- 116 & 268 & 1 & Reputação \\
\hline BB2 & 601 & 225 & 258 & 083 & 208 & ,326 & 130 &,- 178 & 228 & & \\
\hline BB1 & ,596 & , 195 & ,236 & 254 & ,144 & , 402 & , 198 &,- 172 & ,171 & & \\
\hline VP4 & ,173 & 817 & ,039 & ,019 & ,198 & ,234 &, 082 & ,076 & 057 & & Valor do \\
\hline VP2 & , 186 &, 800 & 087 & 186 & ,198 &, 072 & 097 & 037 & ,092 & 2 & Relacionament \\
\hline VP3 & , 167 &, 800 &, 073 & 144 & ,042 &,- 029 & ,023 & ,132 &,- 028 & & o \\
\hline
\end{tabular}


http://www.revista.ufpe.br/gestaoorg

\begin{tabular}{|c|c|c|c|c|c|c|c|c|c|c|c|}
\hline VP1 & 167 & 687 & 284 & ,006 & , 160 & ,011 & 291 & ,081 & , 158 & \multirow{7}{*}{3} & \multirow{7}{*}{$\begin{array}{l}\text { Qualidade do } \\
\text { serviço }\end{array}$} \\
\hline CP3 & ,039 & ,572 & ,044 & ,322 & ,060 & ,289 &,- 026 & ,136 & ,059 & & \\
\hline QS3 & ,254 & ,063 & ,768 & , 154 & 251 & ,196 &,- 017 & ,058 & ,000 & & \\
\hline QS2 & 257 & ,029 & ,730 & , 125 & ,061 & ,021 &,- 074 & ,352 & ,135 & & \\
\hline CF1 & ,308 & 205 & 699 & 250 & ,242 & , 100 & 065 &,- 043 &,- 081 & & \\
\hline CF4 & ,419 & ,092 & ,592 & , 451 & , 170 & ,055 & , 145 & ,156 & , 104 & & \\
\hline SAT4 & 146 & ,319 & ,567 &,- 042 & ,052 & ,278 & 223 & ,064 & 197 & & \\
\hline CF3 & ,162 & 279 & 277 & ,767 & ,153 &,- 010 & 081 &,- 043 & ,098 & \multirow{4}{*}{4} & \multirow{4}{*}{ Confiança } \\
\hline CF2 & 183 & ,416 & 267 & 672 & 225 & ,018 & ,064 &,- 066 & ,006 & & \\
\hline SAT3_R & 264 & ,121 &,- 157 & -596 & 197 & 286 &,- 014 & ,221 & 248 & & \\
\hline QS4 & ,178 & ,029 &, 460 & ,591 & ,016 & ,205 &, 096 &,- 170 &, 048 & & \\
\hline PR1 & ,038 & 065 & , 143 & ,055 & 887 & ,034 & 037 & ,022 & , 131 & \multirow{3}{*}{5} & \multirow{3}{*}{ Preço } \\
\hline PR2 & 102 & ,230 & ,151 & ,142 & ,827 & , 106 &,- 009 & ,003 & ,041 & & \\
\hline PR3 &, 112 & ,205 & ,107 & , 167 & ,759 & ,116 &,- 033 &, 088 &, 048 & & \\
\hline IR2 & ,168 & ,122 & , 100 & , 150 & ,102 & ,746 & ,063 & 212 & $\begin{array}{l}-, 090 \\
\end{array}$ & \multirow[b]{2}{*}{6} & \multirow{2}{*}{$\begin{array}{l}\text { Intenção de } \\
\text { recompra }\end{array}$} \\
\hline IR3 & ,257 & 241 & ,268 & 037 & , 145 & ,648 & ,144 &, 043 &, 274 & & \\
\hline BA4 & 048 & ,078 & ,037 & , 158 & 015 & ,101 & 844 & ,154 & ,066 & \multirow[b]{2}{*}{7} & \multirow{2}{*}{ Custos de troca } \\
\hline BA3 & 156 & 107 &,- 011 &,- 049 &,- 076 & 077 & 842 & 086 & 012 & & \\
\hline CP4 & 055 & ,131 & , 021 & ,034 &,- 004 & , 160 & ,098 & ,786 &,- 140 & \multirow{2}{*}{$\varepsilon$} & \multirow{2}{*}{$\begin{array}{l}\text { Comprometime } \\
\text { nto }\end{array}$} \\
\hline CP1 & 193 & 181 & ,251 &,- 132 &, 059 &, 046 & , 179 & ,712 & ,278 & & \\
\hline BA1_R & , 127 & 082 & , 016 & ,087 & 085 & $\begin{array}{l}-, 018 \\
\end{array}$ &,- 068 &,- 060 & 865 & \multirow[b]{2}{*}{9} & \multirow{2}{*}{$\begin{array}{l}\text { Busca de } \\
\text { alternativas }\end{array}$} \\
\hline BA2_R & 157 & ,091 & ,134 &, 178 & , 124 & ,154 & ,182 & ,069 & ,818 & & \\
\hline IR1 & ,375 & 073 & ,281 &,- 011 &,- 023 & ,353 & ,058 & ,242 & ,348 & \multirow{6}{*}{\multicolumn{2}{|c|}{ Variáveis excluídas }} \\
\hline QS1 & ,311 & ,417 & ,491 & ,401 & ,064 & ,012 &,- 046 & 168 & , 140 & & \\
\hline SAT2 & 242 & ,339 & ,327 & ,313 & 267 & ,047 & ,395 & ,007 & , 182 & & \\
\hline CP5 & ,216 & 283 & ,158 & 208 & 253 & , 123 & ,359 & ,386 &,- 217 & & \\
\hline CP2 & 190 & ,385 & ,307 & 107, & , 196 & ,381 & 297 & ,403 & ,052 & & \\
\hline SAT1_R & , 140 &,- 022 & ,094 & ,447 & ,134 & ,428 & ,201 &, 366 & , 179 & & \\
\hline
\end{tabular}

\subsection{Análise fatorial confirmatória (AFC)}

Para a realização da AFC, conforme orientação de Hair Jr et al. (2014), criou-se um modelo de mensuração com as variáveis observáveis, e um modelo estrutural com os caminhos sugeridos pela teoria, considerando as 31 variáveis resultantes da AFE. O algoritmo para o PLS utilizado foi o sistema de ponderação de caminhos, que oferece o maior valor de R2 (Coeficiente de Determinação) para as variáveis latentes endógenas (valor do relacionamento e intenção de recompra), com peso inicial igual a 1 e 300 iterações. Para a realização dos cálculos, eliminou-se 19 respondentes com dados parcialmente perdidos da amostra de 137, restando para a AFC e para a MEE uma amostra de 118 respondentes.

O modelo estrutural e de mensuração inicialmente proposto baseou-se em proposições de Eggert e Ulaga (2002), Lam et al. (2004), Ulaga e Eggert (2006) e Hansen, Samuelsen e Silseth (2008).

Conforme Eggert e Ulaga (2002), Lam et al. (2004), boca-a-boca pode ser considerado um aspecto da intenção comportamental, e portanto compreendido após a formação do valor percebido. Para Hansen, Samuelsen e Silseth (2008), a reputação é um antecedente do valor percebido. Por isto, mesmo que a AFE tenha juntado as variáveis destes dois construtos (reputação e boca-a-boca), decidiu-se pela separação deles, pois, a técnica da AFE pressupõe que o conjunto de variáveis selecionadas possui alguma estrutura subjacente e a relevância do seu resultado está subordinada a conceitos teóricos, pois a técnica não dispõe de meios para determinar adequação além das correlações entre as variáveis (HAIR JR et al., 2009).

Da mesma forma, seguindo as sugestões de Eggert e Ulaga (2002), construtos de intenção de recompra, busca de alternativas e boca-a-boca foram considerados como consequentes do valor percebido. Por fim, apoiando-se nas indicações de Ulaga e Eggert (2006), confiança e comprometimento foram considerados como consequentes do valor.

Os resultados dos modelos de mensuração e estrutural podem ser vistos na Figura 1 a seguir apresentada.

Para avaliar a validade convergente e validade discriminante no modelo de mensuração, conforme sugestão de Hair Jr et al. (2014) verificou-se incialmente as cargas fatoriais das variáveis observáveis. Segundo este critério, o item CP3 obteve carga abaixo de $0,70(0,678)$, e por isto foi excluído. Os demais valores oscilaram entre 0,73 e 0,95. Já para a análise da AVE - Análise da Variância Extraída (comunalidade de um construto), cujo parâmetro é AVE $>0,50$, não foram identificadas violações de parâmetros e os construtos oscilaram entre 0,63 e 0,89 . 
Igualmente, na Confiabilidade Composta (parâmetro: $\mathrm{CC}>0,70$ ), não houve violação de parâmetros, e os construtos oscilaram entre 0,85 e 0,96 . Vale ressaltar que após a exclusão do item CP3, os Alfas de Cronbach dos construtos permaneceram com valores entre 0,68 e 0,94 .

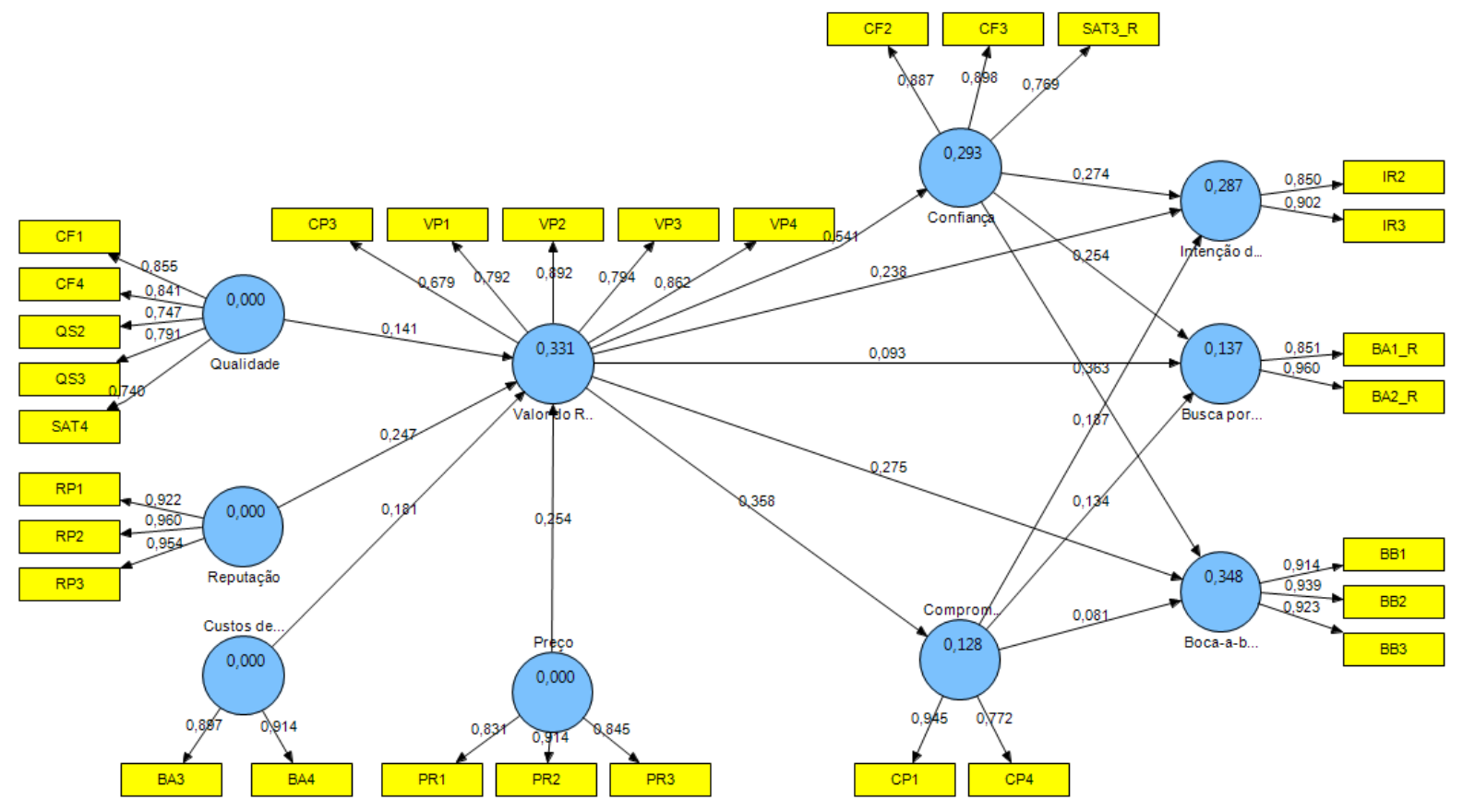

Figura 1: Modelo de mensuração e estrutural inicial

Em relação à validade discriminante, com a aplicação do método Fornell e Lacker, verificou-se que nenhum dos construtos violou o parâmetro, compartilhando mais variância com indicadores de outro construto do que com os seus indicadores. Além disto, examinou-se as cargas transversais dos indicadores, conforme sugerido por Hair $\mathrm{Jr}$ et al. (2014). Neste método, verificou-se que as cargas de cada indicador em seus construtos foram maiores do que as cargas transversais em outros construtos. Portanto, não houve violações de parâmetros.

\subsection{Modelagem de equações estruturais utilizando PLS (MEEPLS)}

Obtidas as validades discriminante e convergente, prosseguiu-se com a análise do modelo estrutural segundo os parâmetros especificados para a MEEPLS.

O coeficiente de caminhos (p) foi comparado com o t-value, para um intervalo de confiança de $95 \%$. Os valores de t-value foram gerados pela técnica de Bootstrapping do SMARTPLS 2.0 M3. A Tabela 2 apresenta os resultados dos coeficientes de caminho e t-value com efeitos totais (soma dos efeitos diretos e indiretos).

A análise de significância obtida por meio do t-value e coeficiente de caminhos, considerando-se os efeitos totais, evidenciou não-significância em diversas relações. Por isto, procedeu-se com uma série de exclusões de construtos/relações até que um modelo mais parcimonioso pudesse apresentar maior capacidade preditiva (Quadro 3). Após a $4^{\mathrm{a}}$ reespecificação, verificou-se que, apesar de o construto preço não estar apresentando relação significante com o construto busca de alternativas, continuava a ter relações significantes com o restante do modelo, principalmente em sua relação direta com o construto valor do relacionamento, motivo pelo qual optou-se por mantê-lo no modelo.

Ainda após a $4^{\mathrm{a}}$ reespecificação, foram mensurados o Coeficiente de Determinação (R2) ajustado, o Coeficiente de Redundância Cross-validado (Q2) e o do Tamanho do Efeito (f2). O R2 ajustado apresentou efeitos pequenos para os construtos endógenos comprometimento e busca de alternativas, razão pela qual a $5^{\mathrm{a}}$ e a $6^{\mathrm{a}}$ reespecificações foram realizadas, conforme Quadro 3. Após a $6^{\text {a }}$ reespecificação, o modelo apresentou os resultados de R2 ajustado, o Q2 e o do f2, conforme Tabelas 3 e 4.

Tabela 2: Coeficientes de Caminhos (p) e t-value - modelo inicial

\begin{tabular}{|c|c|c|c|c|}
\hline Construtos & Caminhos & $p$ & t-value & $\begin{array}{c}\text { Significância } \\
t \text {-value }>1,96\end{array}$ \\
\hline \multirow{3}{*}{$\begin{array}{l}\text { Comprome- } \\
\text { timento }\end{array}$} & Comprometimento $\rightarrow$ Boca-a-boca & 0,083679 & 0,880397 & Não-Significante \\
\hline & Comprometimento $\rightarrow$ Busca de Alternativas & 0,138895 & 1,130583 & Não-Significante \\
\hline & Comprometimento $\rightarrow$ Intenção de Recompra & 0,199148 & 1,943332 & Não-Significante \\
\hline
\end{tabular}


Silva, C. M. S.; Moriguchi, S. N.; Lopes, J. E. F.

Revista Gestão.Org, v. 14, n. 2, 2016. p. 327-342

ISSN 1679-1827

http://www.revista.ufpe.br/gestaoorg

\begin{tabular}{|c|c|c|c|c|}
\hline \multirow{3}{*}{ Confiança } & Confiança $\rightarrow$ Boca-a-boca & 0,372862 & 4,619675 & Significante \\
\hline & Confiança $\rightarrow$ Busca de Alternativas & 0,259582 & 2,495086 & Significante \\
\hline & Confiança $\rightarrow$ Intenção de Recompra & 0,304055 & 3,772019 & Significante \\
\hline \multirow{6}{*}{$\begin{array}{l}\text { Custos } \\
\text { Troca }\end{array}$} & Custos de troca $\rightarrow$ Boca-a-boca & & 1,769685 & Não-Significante \\
\hline & Custos de troca $\rightarrow$ Busca de Alternativas & & 1,320497 & Não-Significante \\
\hline & Custos de troca $\rightarrow$ Comprometimento & & 1,41156 & Não-Significante \\
\hline & Custos de troca $\rightarrow$ Confiança & & 1,893895 & Não-Significante \\
\hline & Custos de troca $\rightarrow$ Intenção de Recompra & & 1,629124 & Não-Significante \\
\hline & Custos de troca $\rightarrow$ Valor do Relacionamento & 0,193122 & 1,834663 & Não-Significante \\
\hline \multirow{6}{*}{ Preço } & Preço $\rightarrow$ Boca-a-boca & & 2,115232 & Significante \\
\hline & Preço $\rightarrow$ Busca de Alternativas & & 1,596199 & Não-Significante \\
\hline & Preço $\rightarrow$ Comprometimento & & 1,663164 & Não-Significante \\
\hline & Preço $\rightarrow$ Confiança & & 1,905675 & Não-Significante \\
\hline & Preço $\rightarrow$ Intenção de Recompra & & 2,041994 & Significante \\
\hline & Preço $\rightarrow$ Valor do Relacionamento & 0,235705 & 2,253427 & Significante \\
\hline \multirow{6}{*}{$\begin{array}{l}\text { Qualidade do } \\
\text { Serviço }\end{array}$} & Qualidade $\rightarrow$ Boca-a-boca & & 1,31648 & Não-Significante \\
\hline & Qualidade $\rightarrow$ Busca & & 1,202355 & Não-Significante \\
\hline & Qualidade $\rightarrow$ Comprometimento & & 1,214143 & Não-Significante \\
\hline & Qualidade $\rightarrow$ Confiança & & 1,246554 & Não-Significante \\
\hline & Qualidade $\rightarrow$ Intenção de Recompra & & 1,304577 & Não-Significante \\
\hline & Qualidade $\rightarrow$ Valor do Relacionamento & 0,144585 & 1,347137 & Não-Significante \\
\hline \multirow{6}{*}{ Reputação } & Reputação $\rightarrow$ Boca-a-boca & & 1,750397 & Não-Significante \\
\hline & Reputação $\rightarrow$ Busca de Alternativas & & 1,481191 & Não-Significante \\
\hline & Reputação $\rightarrow$ Comprometimento & & 1,652577 & Não-Significante \\
\hline & Reputação $\rightarrow$ Confiança & & 1,764383 & Não-Significante \\
\hline & Reputação $\rightarrow$ Intenção de Recompra & & 1,682185 & Não-Significante \\
\hline & Reputação $\rightarrow$ Valor do Relacionamento & 0,235404 & 1,985074 & Significante \\
\hline \multirow{5}{*}{$\begin{array}{l}\text { Valor } \\
\text { Relacion. }\end{array}$} & Valor do Relacionamento $\rightarrow$ Boca-a-boca & 0,277027 & 6,667038 & Significante \\
\hline & Valor do Relacion. $\rightarrow$ Busca de Alternativas & 0,091069 & 2,683656 & Significante \\
\hline & Valor do Relacionamento $\rightarrow$ Comprometimento & 0,344745 & 3,25192 & Significante \\
\hline & Valor do Relacionamento $\rightarrow$ Confiança & 0,499465 & 5,722582 & Significante \\
\hline & Valor do Relacion. $\rightarrow$ Intenção de Recompra & 0,194491 & 5,314181 & Significante \\
\hline
\end{tabular}

Tabela 3: Resultados de $\mathrm{R}^{2}$ Ajustado e $\mathrm{Q}^{2}$ - com a exclusão dos construtos Comprometimento e Busca de Alternativas

\begin{tabular}{|c|c|c|c|c|}
\hline Construto & $\mathbf{R}^{2}$ Ajustado & Resultado & $\mathbf{Q}^{2}$ & Resultado \\
\hline & $\begin{array}{r}\text { Parâmetros: } 2 \% \\
\text { - efeito médio }\end{array}$ & $\begin{array}{l}\text { ito pequeno; } 13 \% \\
\text { - efeito grande }\end{array}$ & \multicolumn{2}{|c|}{ Parâmetro: $\mathrm{Q}^{2}>0$} \\
\hline Boca-a-Boca & 0,35 & Efeito Grande & 0,289014 & Adequado \\
\hline Confiança & 0,25 & Efeito Médio & 0,185942 & Adequado \\
\hline Intenção de Recompra & 0,24 & Efeito Grande & 0,189103 & Adequado \\
\hline Valor do Relacionam. & 0,27 & Efeito Grande & 0,177274 & Adequado \\
\hline
\end{tabular}

Tabela 4: Resultados de $\mathrm{f}^{2-}$ - com a exclusão dos construtos Comprometimento e Busca de Alternativas

\begin{tabular}{|c|c|c|c|c|}
\hline \multirow[b]{2}{*}{ Construto Endógeno } & \multicolumn{4}{|c|}{$\begin{array}{l}\text { Construto Excluído para Análise do Efeito }\left(\mathbf{f}^{\mathbf{2}}\right) \\
\text { Parâmetro: } 0,02 \text { - pequeno; } 0,15 \text { - médio; } 0,35 \text { - grande }\end{array}$} \\
\hline & \multicolumn{2}{|c|}{ Reputação } & \multicolumn{2}{|c|}{ Preço } \\
\hline Boca-a-Boca & 0,004688 & Pequeno & 0,004887 & Pequeno \\
\hline Confiança & 0,002564 & Pequeno & 0,003136 & Pequeno \\
\hline Intenção de Recompra & 0,002329 & Pequeno & 0,00334 & Pequeno \\
\hline Valor do Relacionam. & 0,179538 & Médio & 0,095406 & Pequeno \\
\hline
\end{tabular}


Quadro 3: Reespecificações realizadas

\begin{tabular}{|c|c|c|}
\hline $\begin{array}{l}\text { Reespecifica } \\
\text { ção }\end{array}$ & Alteração & Resultado \\
\hline $1^{\mathrm{a}}$ & $\begin{array}{l}\text { Exclusão do construto exógeno qualidade do } \\
\text { serviço. Motivo: apresentou menor coeficiente de } \\
\text { caminhos dentre os construtos exógenos e todas as } \\
\text { relações (efeitos totais) não-significantes. }\end{array}$ & $\begin{array}{l}\text { Relações não- significantes: } \\
\text { Comprometimento } \rightarrow \text { Boca-a-boca } \\
\text { Comprometim. } \rightarrow \text { Busca de Alternativas } \\
\text { Custos de troca } \rightarrow \text { Boca-a-boca } \\
\text { Custos de troca } \rightarrow \text { Busca de Alternativas } \\
\text { Custos de troca } \rightarrow \text { Comprometimento } \\
\text { Custos de troca } \rightarrow \text { Intenção de Recompra } \\
\text { Preço } \rightarrow \text { Busca de Alternativas }\end{array}$ \\
\hline $2^{\mathrm{a}}$ & $\begin{array}{l}\text { Exclusão do construto exógeno custos de troca. } \\
\text { Motivo: apresentou menor coeficiente de } \\
\text { caminhos dentre os construtos exógenos e quase } \\
\text { todas as relações (efeitos totais) não-significantes. }\end{array}$ & $\begin{array}{l}\text { Relações não- significantes: } \\
\text { Comprometimento } \rightarrow \text { Boca-a-boca } \\
\text { Comprometim. } \rightarrow \text { Busca de Alternativas } \\
\text { Preço } \rightarrow \text { Busca de Alternativas } \\
\text { Preço } \rightarrow \text { Comprometimento }\end{array}$ \\
\hline $3^{\mathrm{a}}$ & $\begin{array}{l}\text { Exclusão da relação Comprometimento } \rightarrow \text { Boca- } \\
\text { a-boca, que apresentou menor coeficiente de } \\
\text { caminho e maior não-significância }\end{array}$ & $\begin{array}{l}\text { Relações não- significantes: } \\
\text { Comprometim. } \rightarrow \text { Busca de Alternativas } \\
\text { Preço } \rightarrow \text { Busca de Alternativas } \\
\text { Preço } \rightarrow \text { Comprometimento }\end{array}$ \\
\hline $4^{\mathrm{a}}$ & $\begin{array}{l}\text { Exclusão da relação Comprometimento } \rightarrow \text { Busca } \\
\text { de Alternativas, que apresentou menor coeficiente } \\
\text { de caminho e maior não-significância dentre as } \\
\text { relações não-significantes identificadas }\end{array}$ & $\begin{array}{l}\text { Relações não- significantes: } \\
\text { Preço } \rightarrow \text { Busca de Alternativas }\end{array}$ \\
\hline $5^{\mathrm{a}}$ & $\begin{array}{l}\text { Exclusão do construto comprometimento, que } \\
\text { apresentou } \mathrm{Q}^{2}=0,069094 \text { e } \mathrm{R}^{2} \text { Ajustado }=0,11 \\
\text { (Efeito Pequeno) }\end{array}$ & $\begin{array}{l}\text { Relações não- significantes: } \\
\text { Preço } \rightarrow \text { Busca de Alternativas }\end{array}$ \\
\hline $6^{\mathrm{a}}$ & $\begin{array}{l}\text { Exclusão do construto busca de alternativas, que } \\
\text { apresentou } \mathrm{Q}^{2}=0,072357 \text { e } \mathrm{R}^{2} \text { Ajustado }=0,12 \\
\text { (Efeito Pequeno) }\end{array}$ & Sem relações não significantes \\
\hline $7^{\circ}$ & $\begin{array}{l}\text { Exclusão do construto preço. Motivo: apesar de } \\
\text { apresentar relações significantes no modelo, não } \\
\text { apresentou efeito significativo em todos os } \\
\text { construtos endógenos }\end{array}$ & $\begin{array}{l}\text { Sem relações não significantes. Sem } \\
\text { alterações significativas nos indicadores de } \\
\mathrm{R}^{2} \text { Ajustado, } \mathrm{Q}^{2} \mathrm{e} \mathrm{f}^{2 .}\end{array}$ \\
\hline
\end{tabular}

Após a exclusão do construto Preço, estabeleceu-se um modelo final reespecificado conforme a Figura 2: 


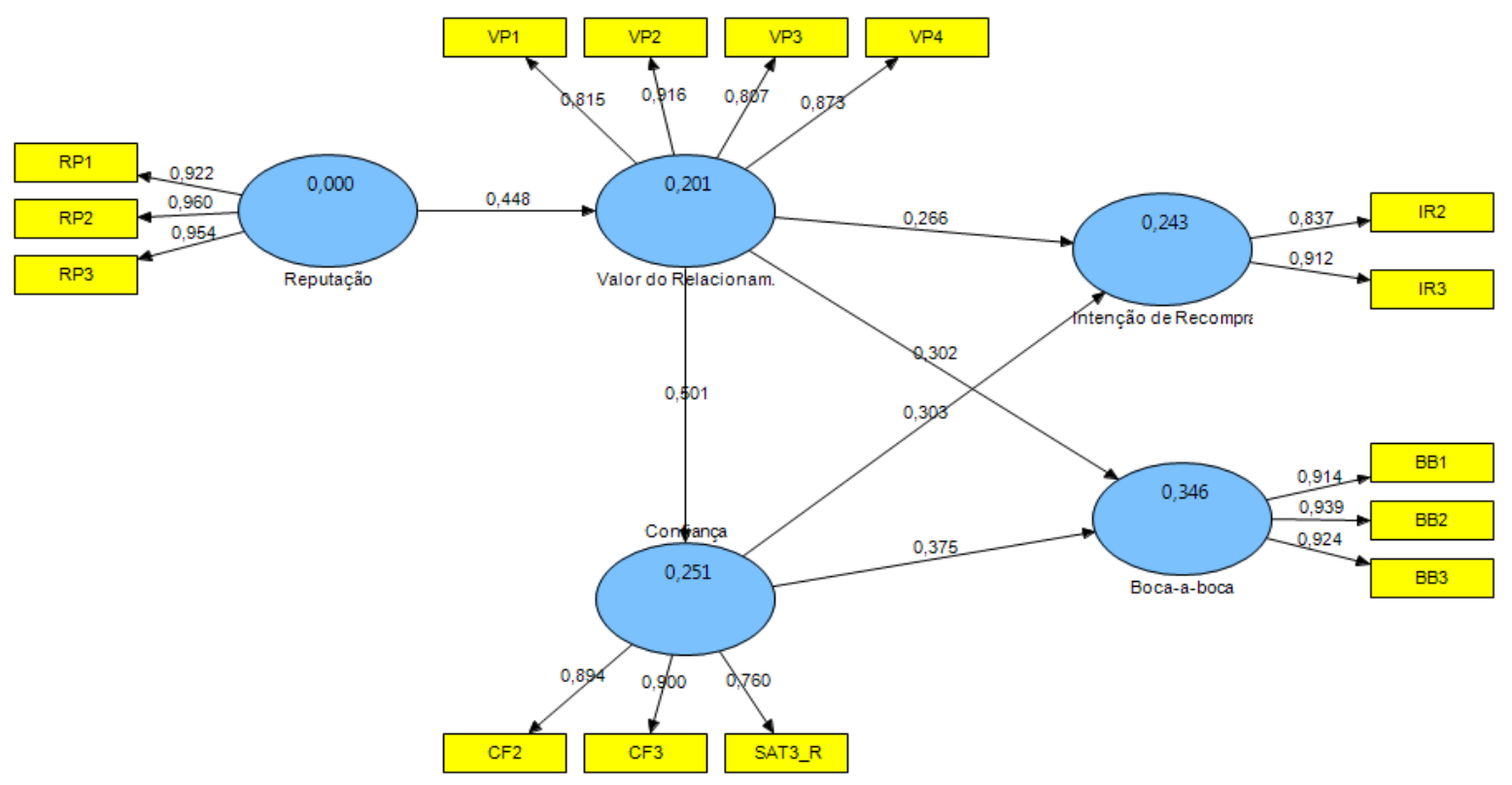

Figura 2: Modelo reespecificado final

O modelo final é composto por 5 construtos (reputação, valor do relacionamento, confiança, intenção de recompra e boca-a-boca), com 15 variáveis. A $7^{\mathrm{a}}$ reespecificação não alterou significativamente os resultados do R2 ajustado, do Q2 e o do f2 (para o construto reputação) apresentados nas Tabelas 3 e 4. Os resultados de tvalue e coeficientes de caminhos para o modelo reespecificado final encontram-se na Tabela 5.

Tabela 5 - Coeficientes de Caminhos (p ) e t-value - Modelo Reespecificado Final

\begin{tabular}{llccc}
\hline \multirow{2}{*}{ Construtos } & \multicolumn{1}{c}{ Caminhos } & p & t-value & $\begin{array}{c}\text { Significância } \\
\text { t-value }>\mathbf{1 , 9 6}\end{array}$ \\
\cline { 3 - 5 } Confiança & Confiança $\rightarrow$ Boca-a-boca & 0,374786 & 4,199025 & Significante \\
& Confiança $\rightarrow$ Intenção de Recompra & 0,302617 & 3,226854 & Significante \\
\hline \multirow{2}{*}{ Reputação } & Reputação $\rightarrow$ Boca-a-boca & & 3,060976 & Significante \\
& Reputação $\rightarrow$ Confiança & & 2,851889 & Significante \\
& Reputação $\rightarrow$ Intenção de Recompra & & 2,861661 & Significante \\
& Reputação $\rightarrow$ Valor do Relacionamento & 0,447807 & 4,956044 & Significante \\
\hline Valor & Relaciona- \\
mento & Valor do Relacionamento $\rightarrow$ Boca-a-boca & 0,302379 & 6,275171 & Significante \\
& Valor do Relacionamento $\rightarrow$ Confiança & 0,501279 & 5,385509 & Significante \\
\hline
\end{tabular}

A seguir, os resultados são discutidos à luz dos objetivos propostos.

\section{Discussão dos Resultados}

Os 5 construtos do modelo final reespecificado - reputação, valor do relacionamento, confiança, intenção de recompra e boca-a-boca - estão em conformidade com a teoria e estudos aplicados na área de percepção de valor, pois extrapolam as avaliações de atributos observáveis e lançam novo olhar sobre mensuração de alta abstração.

A exclusão dos construtos qualidade do serviço, custos de troca, preço, comprometimento e busca de alternativas do modelo inicial deveu-se à construção de um modelo de mensuração de valor percebido em serviços logísticos mais parcimonioso, e a técnica de MEEPLS permitiu uma visão mais adequada das relações significantes e da acurácia preditiva de cada um dos construtos. A despeito da importância destes construtos em modelos de mensuração de valor percebido para a literatura em geral, verifica-se que, para a amostra pesquisada, tais construtos não apresentaram relevância significativa para permanecerem no modelo proposto. Tanto os construtos mantidos como os excluídos do modelo final proposto são a seguir discutidos.

\subsection{Qualidade do serviço}

A qualidade do serviço, apesar de um importante construto para a formação do que se conhece em valor percebido como benefício (ZEITHAML, 1988), na amostra pesquisada, apresentou-se pouco relevante quando 
comparado com a importância da reputação, considerada aqui um benefício mais relevante, onde a qualidade do serviço provavelmente esteja intrínseca.

\subsection{Preço}

No que tange ao preço, vale relembrar que as variáveis escolhidas (PR1, PR2 e PR3) foram oriundas do trabalho que Eggert e Ulaga (2002), cuja sugestão de 'preço razoável' remetia a uma avaliação cognitiva de valor. Desta forma, é provável que as variáveis do consutructo valor do relacionamento - VP1 e VP4 - façam este papel na escala proposta, mensurando em duas variáveis a ideia do construto preço. Por isto, é possível que a amostra pesquisada avalie preços de forma subjetiva. $\mathrm{O}$ construto preço não apresentou efeito (f2) relevante no modelo, motivo pelo qual foi excluído, evidenciando seu pouco impacto na formação do valor do relacionamento.

\subsection{Custos de troca e busca de alternativas}

A relevância da reputação no modelo pode ajudar na compreensão do comportamento das PMEs na formação da percepção de valor para a amostra pesquisada. Custos de troca ou Busca de alternativas parecem pouco relevantes, uma vez que o valor para as PMEs parece focar-se em evidências de reputação como um todo, como forma de resguardar-se de problemas no relacionamento e garantindo serviços de qualidade aceitável. Para estes empreendedores, o risco de errar na escolha de um parceiro logístico pode refletir em sua própria sobrevivência. Por isto, a busca de alternativas e a avaliação dos custos de troca parecem tornar-se pouco relevantes diante da reputação.

\subsection{Comprometimento}

$\mathrm{O}$ construto comprometimento, apesar de intrinsecamente ligado à confiança, mas distinto desta (SUH; HOUSTON, 2010), está ligado à ideia de que o cliente compromete-se em permanecer em um relacionamento. O construto poderia relacionar-se bem com a fidelidade e a retenção dos clientes, que no caso das PMEs parece apontar para trocas relacionais de compra ao invés de apenas transacionais.

As variáveis que compunham o construto comprometimento são oriundas do trabalho de Ulaga e Eggert (2006), os quais compreendem o comprometimento como um estabilizador da relação. Na pesquisa, os autores verificaram que o comprometimento possui correlação com a intenção de expandir ou encerrar um relacionamento, diferentemente da confiança, que afeta o comprometimento, mas não influencia diretamente na intenção de expandir ou encerrar um relacionamento. Os resultados da presente pesquisa diferem de Ulaga e Eggert (2006), revelando dificuldades das PMEs com o aspecto da importância da sua relação com o seu fornecedor de serviços logísticos.

Tal resultado do construto comprometimento remete também aos achados de Martins e Xavier (2011), que identificaram que as PMEs enquanto clientes, ao atribuírem menores notas aos construtos relacionamento com os clientes e atendimento às necessidades especiais, dão indícios de que aceitam a comoditização do serviço de transportes. Este comportamento, segundo tais autores, pode ser explicado tanto pelos pequenos volumes embarcados como pela baixa frequência de consumo de serviços logísticos, se comparados aos grandes consumidores empresariais. Por isto, os provedores de serviços logísticos deste mercado podem não se preocupar com a melhoria de seus níveis de serviço para o segmento de PMEs. Do lado dos demandantes (PMEs), quando percebem este gap entre o que desejam e o que recebem (Martins et al., 2011), podem não buscar o comprometimento em suas relações, razão pela qual tal construto pode não ter se sustentado no modelo.

\subsection{Reputação}

O constucto reputação foi identificado com as maiores cargas fatoriais na AFE, em conjunto com o boca-a-boca. A alta correlação encontrada entre a reputação e boca-a-boca sustenta-se em estudos como os de Gosling e Lago (2006), Ulaga e Eggert (2002), Lam et al. (2004), Molinari, Abratt e Dion(2008), Hansen, Samuelsen e Silseth (2008). A junção das variáveis ligadas à reputação corporativa e o boca-a-boca evidencia que, no caso de PMEs, a escolha do parceiro logístico leva em conta sua reputação como um todo, pois erros logísticos refletem em grandes problemas para o pequeno negócio. Esta constatação pode ser reforçada quando traz-se à tona o contexto da gestão da cadeia de suprimentos para a PME: a escassez de recursos financeiros, pessoas, sistemas e conhecimento técnico, o forte componente familiar, a centralização na gestão e o envolvimento pessoal do dono nas decisões e atividades funcionais, muitas vezes de maneira não planejada, impactando negativamente em seus resultados (DRUMOND; TOALDO, 2009). Os resultados sugerem que a escolha de um parceiro logístico de boa reputação pode minimizar riscos e diminuir problemas na gestão das PMEs.

\subsection{Valor do relacionamento}

Na mesma perspectiva do que foi apresentado na reputação, o valor percebido, para a amostra pesquisada, indica que o valor é entendido na lida da relação com o fornecedor de serviços logísticos. O construto valor do relacionamento encontra apoio na literatura de estudos aplicados de percepção de valor. Vale ressaltar que Ravald e Grönroos (1996) associam a formação da percepção de valor aos diversos episódios vividos pelo cliente. Em se tratando de um ambiente B2B de prestação contínua de serviços logísticos, o valor do 
relacionamento torna-se um construto de evidente importância. No Brasil, o estudo de Martins et al. (2011) com PMEs, encontrou o construto "Relacionamento com o cliente", que abordava atributos como "Disposição para ouvir e agir no caso de comunicação de falhas ou problemas" e "Atendimento educado e cortês".

Os resultados apresentados na presente pesquisa podem indicar que, de fato, PMEs estão interessadas em relacionar-se de maneira mais emocional e íntima com seus parceiros logísticos. Suas preocupações acerca da boa escolha do parceiro logístico levam em conta o tipo de relacionamento, tanto quanto sua reputação.

\subsection{Confiança}

No que tange ao construto confiança, inicialmente deve-se destacar este não pode ser confundido com o construto confiabilidade. Na presente pesquisa, a confiança deriva da confiabilidade, solicitando do respondente uma avaliação mais abstrata de preocupação do parceiro logístico em dar o melhor de si para servir ao cliente, sendo algo que sustenta relação.

Suh e Houston (2010) distinguem dois tipos de confiança na relação fornecedor-cliente B2B: confiança ligada à boa vontade com a relação como um todo, ou a confiança ligada à integridade, que por sua vez refere-se à sinceridade do fornecedor. Na presente pesquisa, o construto confiança está mais ligado ao conceito de boa vontade do fornecedor.

Cumpre destacar que os respondentes, em sua maioria, avaliaram seus parceiros logísticos de maneira negativa em relação a esta preocupação com os interesses dos PMEs. Apenas 35\% concordaram de alguma maneira, que o parceiro logístico considera o bem-estar das PMEs na hora de tomar decisões (CF3). Apenas 44\% concordaram de alguma maneira, estarem felizes com seu atual parceiro logístico (SAT3_R). Os percentuais apresentados podem denotar uma lacuna na construção da confiança dos parceiros logísticos junto às PMEs. Possivelmente, a ausência clara de segmentação de mercados logísticos no Brasil, conforme apontam Figueiredo e Mora (2009), dificulte a prestação de serviços logísticos que gerem a percepção de confiança satisfatória em seus clientes.

\subsection{Boca-a-boca}

O conceito de lealdade recomendada (boca-a-boca), utilizado na pesquisa de Lam et al. (2004) e fonte para a construção da presente pesquisa, parece aderir bem à reputação de um operador logístico. No que se refere ao resultado de altas variâncias compartilhadas entre reputação de boca-a-boca na presente pesquisa, verifica-se na literatura tal recorrência. Hansen, Samuelsen e Silseth (2008), ao investigarem a reputação corporativa na formação da percepção de valor em serviços de telefonia no ambiente $\mathrm{B} 2 \mathrm{~B}$, encontraram, dentre todos os construtos estudados, maiores cargas fatoriais no construto Boca-a-boca (AVE: 0,89). Na mesma direção, Janita e Miranda (2013) encontraram maiores cargas fatoriais nos construto de Imagem (AVE: 0,88), ligado às questões de reputação, quando estudaram a formação da percepção de valor no setor de e-marketplaces na Espanha.

O presente estudo revelou o boca-a-boca como o mais relevante construto consequente do modelo, com os melhores indicadores de R2 ajustado, o Q2 e f2, dentre todos os construtos endógenos, indicando grande importância desta intenção comportamental para a acurácia preditiva do modelo proposto.

\subsection{Intenção de recompra}

$\mathrm{Na}$ intenção de recompra, vale ressaltar que a AFE indicou que a variável IR1 (intenção de recompra no curtíssimo prazo) deveria ser excluída devido à carga cruzada. As duas variáveis IR2 e IR3 parecem sugerir que, nas relações com o parceiro logístico, por ser um serviço que precisa ser consumido de forma contínua, os consumidores B2B consideram relações mais duradouras e menos transacionais, e em consonância com estudos de valor no ambiente B2B, tais como Patterson e Spreng (1997), Eggert e Ulaga (2002), Ulaga e Eggert (2006) Rauyruen e Miller (2007), Molinari, Abratt e Dion (2008).

Por ser considerada uma medida de fidelidade objetiva de um consumidor e geradora de vantagem competitiva (Woodruff, 1997; Parasunaman, 1997), no modelo final proposto, a intenção de recompra figurou-se como o segundo construto de maior relevância (R2) e acurácia preditiva (Q2) no modelo, sendo esta constatação uma evidência de que o modelo oferece condições para ser usado em mensurações de valor percebido.

\section{Conclusão}

O campo de compreensão do fenômeno de percepção de valor é amplo e abstrato. Considerando a lacuna teórica e aplicada existente no Brasil na área logística de PMEs, a análise apresentada é um passo dado em direção às investigações futuras neste campo, pois métricas de valor continuam a ser importantes para obter e manter vantagem competitiva (WOODRUFF, 1997; PARASUNAMAN, 1997).

Este resultado recomenda que fornecedores de serviços logísticos para PMEs brasileiras considerem, em conjunto com atributos objetivos e observáveis de avaliação de seus clientes, dimensões de alta abstração, tais como reputação, valor do relacionamento, confiança, intenção de recompra e boca-a-boca. As evidências apresentadas neste estudo sugerem que as PMEs buscam fornecedores de serviços logísticos de boa reputação como forma de minimizar problemas na gestão da cadeia de suprimentos, já que encontram-se em desvantagens de recursos perante grandes corporações para barganhar por melhores serviços. 
Sugere-se que o instrumento proposto seja novamente testado, se possível com uma amostra gerada através de um processo probabilístico, pois a amostragem por conveniência apresenta-se como uma limitação desta pesquisa.

\section{Referências}

BARDIN, L. Análise de conteúdo. São Paulo: Edições 70, 2011.

BLOCKER, C. P. Modeling customer value perceptions in cross-cultural business markets. Journal of Business Research, v. 64, n.5, p.533-540, 2011.

BOCKSBERGER, P. E.; MELSEN, L. Perceived value: a critical examination of definitions, concepts and measures for the service industry. Journal of Services Marketing, v. 25, n. 3, p. 228-240, 2011.

BOWMAN, C.; AMBROSINI, V. Value creation versus value capture: towards a coherent definition of value in strategy. British Journal of Management, v.11, n.1, p. 1-15, 2000.

BREI, V. A.; ROSSI, C. A. V. Confiança, valor percebido e lealdade em trocas relacionais de serviço: um estudo com usuários de internet banking no Brasil. Revista de Administração Contemporânea, v. 9. N. 2, pp. 145 $168,2005$.

BRADY, M. K.; CRONIN JR, J. J. Some new thoughts on conceptualizing perceived service quality: a hierarchical approach. Journal of Marketing, v. 65, n. 3, pp. 34-49, 2001.

CONFEDERAÇÃO NACIONAL DOS TRANSPORTES (CNT). Plano CNT de transporte e logística 2014. 2014. Disponível em: <http://www.cnt.org.br/Paginas/Plano-CNT-de-Log\%C3\%ADstica.aspx>. Acesso em: 25 set. 2014.

DRUMOND, M.; TOALDO, A. M. M. Implementação de estratégias de marketing, competitividade e fornecimento de valor em PMEs. In: ENCONTRO DA ANPAD -EnAnpad, 36, 2009, São Paulo. Anais.. São Paulo, SP: ANPAD. 2009. p. 1-16

EGGERT, A.; ULAGA, W. Customer perceived value: a substitute for satisfaction in business markets? Journal of Business \& Industrial Marketing, v. 17, n. 2/3, p. 107-118, 2002.

ELRAM, L. M.; TATE, W. L.; BILLINGTON, C. Understanding and managing the services supply chain. The Journal of Supply Chain Management, p. 17-32, 2004.

ELRAM, L. M.; TATE, W. L.; BILLINGTON, C. Services supply management: the next frontier for improved organizational performance. California Management Review, v. 49, n.4, p. 44-66, 2007.

Figueiredo, K. et al. Segmentação logística: um estudo na relação entre fornecedores e varejistas no Brasil. Revista de Administração Contemporânea, v.11, n.4, p. 11-31, 2007.

FIGUEIREDO, K. F.; MORA, D. M. M. A Segmentação dos Operadores Logísticos no Mercado Brasileiro de acordo com suas Capacitações para Oferecer Serviços. RAC-Eletrônica, v. 3. n.1, p. 123-141, 2009.

FORNELL, C. et al. The American customer satisfaction index: nature, purpose, and findings. The Journal of Marketing, v. 60, n. 4, p. 7-18, 1996.

GEYSKENS, I.; STEENKAMP, J.-B.; KUMAR, N. A meta-analysis of satisfaction in marketing channel relationships, Journal of Marketing Research, v. 36, n.2, p. 223-38, 1999.

GIL-SAURA, I.; FRASQUET-DELTORO, M.; CERVERA-TAULET, A. The value of B2B relationships. Industrial Management \& Data Systems, v.109, n.5, p. 593-609, 2009.

GOSLING, M.; LAGO, J. Dimensões do valor percebido e a influência no boca-a-boca: reflexões teóricas e proposição de um modelo. Revista Eletrônica de Administração, v. 12, n. 5, p. 345-368, 2006.

GRÖNROOS, C.; VOIMA, P. Critical service logic: making sense of value creation and co-creation. Journal of the Academy of Marketing Science, v.41, n.2, p. 133-150, 2013.

HAIR JR, J. F. et. al. Fundamentos de métodos de pesquisa em administração. Porto Alegre: Bookman, 2005. 
HAIR, J. F. et al. Análise multivariada de dados. Porto Alegre: Bookman, 2009.

HAIR JR, J. F. et al. A primer on partial least squares structural equation modeling (PLS-SEM). Thousand Oaks: SAGE Publications, 2014.

HANSEN, H.; SAMUELSEN, B. M.; SILSETH, P. R. Customer perceived value in BtB service relationships: Investigating the importance of corporate reputation. Industrial Marketing Management, v. 37, n. 2, p. 206$217,2008$.

HONG, P.; JEONG, J. Supply chain management practices of SMEs: from a business growth perspective. Journal of Enterprise Information Management, v. 19, n. 3, p. 292-302, 2006.

JANITA, M. S.; MIRANDA, F. J. The antecedents of client loyalty in business-to-business (B2B) electronic marketplaces. Industrial Marketing Management, v. 42, n. 5, p. 814-823, 2013.

LACERDA, T. S.; MENDONÇA, B. Q. Marketing B2B: mapeamento dos trabalhos acadêmicos no Brasil de 1998 a 2007. Revista de Administração da UFSM, v. 3, n. 2, p. 219-229, 2010.

LAM, S. Y et al. Customer value, satisfaction, loyalty, and switching costs: an illustration from a business-tobusiness service context. Journal of the Academy of Marketing Science, v. 32, n. 3, pp. 293-311, 2004.

LAPIERRE, J. Customer-perceived value in industrial contexts. Journal of Business \& Industrial Marketing, v. $15 ;$ n. $2 / 3$, p. $122-145,2000$.

LINDGREEN, A. et al. Value in business and industrial marketing: Past, present, and future. Industrial Marketing Management, v. 41, n.1, p. 207-214, 2012.

MARTINS, R. S. et al. Gestão do Transporte Orientada para os Clientes: Nível de Serviço Desejado e Percebido. RAC-Revista de Administração Contemporânea, v. 15, n. 6, p. 1100-1119, 2011.

MARTINS, R. S.; XAVIER, W. S. Atributos do Serviço de Transporte no Relacionamento Indústria-Varejo. Revista Brasileira de Gestão de Negócios, v. 13, n. 39, p. 193-204, 2011.

MELlO, S. C. B. D.; LEÃO, A. L. M. D. S. Uma Revisão Crítica Uma Revisão Crítica sobre o Uso de Diferentes Conceitos de Valor no Marketing. RAC-Eletrônica, v. 2, n. 1, p. 37-53, 2008.

MOLINARI, L. K.; ABRATT, R.; DION, P. Satisfaction, quality and value and effects on repurchase and positive word-of-mouth behavioral intentions in a B2B services context. Journal of Services Marketing, v. 22 , n. 5 , p. 363-373, 2008.

PARASURAMAN, A.; ZEITHAML, V. A.; BERRY, L. L. A conceptual model of service quality and its implications for future research. The Journal of Marketing, v. 49, p. 41-50, 1985.

PARASURAMAN, A. Reflections on gaining competitive advantage through customer value. Journal of the Academy of Marketing Science, v. 25, n.2, p. 154-161, 1997.

PATTERSON, P. G.; SPRENG, R. A. Modelling the relationship between perceived value, satisfaction and repurchase intentions in a business-to-business, services context: an empirical examination. International Journal of Service Industry Management, v. 8, n. 5, p. 414-434, 1997.

PEREIRA, G. M. D. C.; PEREIRA, S. C. F. Envolvimento dos profissionais de compras na contratação de serviços. In: ENCONTRO DA ANPAD - EnAnpad, 33, 2014, Rio de Janeiro. Anais... Rio de Janeiro, RJ: ANPAD. 2014. p. 1-16.

PRESUTTI JR, W. D.; MAWHINNEY, J. R. Supply Chain - Finance Link. Supply Chain Management Review, p.32-38, 2007.

RAUYRUEN, P.; MILLER, K. E. Relationship quality as a predictor of B2B customer loyalty. Journal of Business Research, v. 60, n. 1, p. 21-31, 2007.

DA ROCHA, A.; SILVA, J. F. da. Marketing de serviços: retrospectiva e tendências. Revista de Administração de Empresas. [online], v. 46, n.4, p. 1-9, 2006. 
SERVIÇO DE APOIO ÀS MICRO E PEQUENAS EMPRESAS (SEBRAE). Anuário das Pesquisas sobre as Micro e Pequenas Empresas (2011). 2012. Disponível em: $<$ http://www.sebrae.com.br/estudos-e-pesquisas.> . Acesso em 26 abr. 2014.

SOUSA-E-SILVA, C. M.; MORIGUCHI, S. N.; LOPES, J. E. F. Proposing a model for measuring the perceived value for B2B logistics environment. In: IAMOT Conference, 24, 2015, Cape Town. Procedures..., Cape Town: IAMOT, 2015. p. 1-18

SPITERI, J. M.; DION, P. A. Customer value, overall satisfaction, end-user loyalty, and market performance in detail intensive industries. Industrial Marketing Management, v. 33, n. 8, p. 675-687, 2004.

SUH, T.; HOUSTON, M. B. Distinguishing supplier reputation from trust in buyer-supplier relationships. Industrial Marketing Management, v. 39, n. 5, p. 744-751, 2010.

TONTINI, G.; ZANCHETT, R. Atributos de satisfação e lealdade em serviços logísticos. Gestão \& Produção, v. 17, n. 4, p. 801-816, 2010.

ULAGA, W. Customer value in business markets: an agenda for inquiry. Industrial Marketing Management, v. 30, n. 4, p. 315-319, 2001.

ULAGA, W.; CHACOUR, S. Measuring customer-perceived value in business markets: a prerequisite for marketing strategy development and implementation. Industrial Marketing Management, v. 30, n. 6, p. 525$540,2001$.

ULAGA, W.; EGGERT, A. Relationship value and relationship quality: Broadening the nomological network of business-to-business relationships. European Journal of Marketing, v. 40, n. 3/4, p. 311-327, 2006.

WIERSEMA, F. The B2B Agenda: The current state of B2B marketing and a look ahead. Industrial Marketing Management, v. 42, n. 4, p. 470-488, 2013.

WOODRUFF, R. B. Customer value: the next source for competitive advantage. Journal of the Academy of Marketing Science, v. 25, n. 2, p. 139-153, 1997.

ZEITHAML, V. A. Consumer perceptions of price, quality, and value: a means-end model and synthesis of evidence. The Journal of Marketing, v. 52, p. 2-22, 1988. 